\title{
Dexamethasone treatment fails to increase arginine-induced insulin release in healthy subjects with low insulin response
}

\author{
V. Grill, M. Alvarsson and S. Efendic \\ Department of Endocrinology, Karolinska Hospital, Stockholm, Sweden
}

\begin{abstract}
Summary. We have compared insulin responses to L-arginine before and during dexamethasone treatment in healthy subjects, previously classified as subjects with either high or low insulin response according to a standardized glucose infusion test. Arginine stimulation was administered as a $150 \mathrm{mg} / \mathrm{kg}$ bolus followed by $10 \mathrm{mg} \cdot \mathrm{kg}^{-1} \cdot \mathrm{min}^{-1}$ to six subjects with high insulin response and to seven subjects with low insulin response. Before dexamethasone treatment the incremental insulin level during $0-10 \mathrm{~min}$ of arginine was higher in subjects with high $(36.5 \pm 6.8 \mu \mathrm{U} / \mathrm{ml})$ than in subjects with low response $(14.5 \pm 2.3 \mu \mathrm{U} / \mathrm{ml}), p<0.01$ for difference. Dexamethasone treatment $(6 \mathrm{mg} /$ day for $60 \mathrm{~h}$ ) markedly enhanced the insulin response to arginine in subjects with high
\end{abstract}

response $(+99 \% 0-30 \mathrm{~min})$ but failed to affect the subjects with low response $(+4 \% 0-30 \mathrm{~min})$. The C-peptide response to arginine exhibited similar differences between groups. Decreased responsiveness to arginine in subjects with low insulin response, especially during dexamethasone treatment, suggests a Beta-cell capacity defect although a decreased potentiating-sensing effect of glucose cannot be completely ruled out.

Key words: Insulin secretion, Type 2 (non-insulin-dependent) diabetes mellitus, glucagon secretion, C-peptide, arginine, dexamethasone.
Insulin responses to glucose vary widely between healthy subjects [1]. Using a standardized glucose infusion test (GIT) we have demonstrated that some subjects display a low insulin response similar to that observed in Type 2 (non-insulin-dependent) diabetes mellitus. It is of clinical interest to characterize these subjects with low insulin response (LIR) since they may have an increased propensity to develop Type 2 diabetes later in life [2,3]. Pursuing such characterization we have demonstrated that LIR do not increase glucose-induced insulin secretion during treatment with dexamethasone to the same extent as subjects with high insulin response (HIR) [4]. These findings imply that the low insulin response to glucose is coupled to a low degree of adaptation to increased demands on the insulinproducing Beta cells, brought about by the insulin-antagonistic actions of glucocorticoids.

These previous studies concerned only glucose-induced insulin secretion. It is not clear whether they reflect glucose-specific and/or more generalized limitations of insulin secretion in LIR. A study of insulin responses to a non-glucose secretagogue such as arginine would provide information on this point. A previous study indicated a reduced insulin response to arginine in LIR [5]. However, the previous study was designed to evaluate primarily glu- cagon responses to arginine and, furthermore, did not test whether arginine-induced insulin secretion was adaptable to insulin resistance in LIR. Recent studies have highlighted the profound influence that the resistance parameter normally exerts on arginine-induced insulin secretion [6]. In this study, we have compared arginine-induced insulin secretion before and during dexamethasone treatment in HIR and LIR.

\section{Subjects and methods}

\section{Subjects}

Subjects previously characterized as HIR or LIR and who had, furthermore, participated in previous studies using dexamethasone [4] were selected. All had normal glucose tolerance as assessed by World Health Organisation criteria [7]. Initial characterization was done from a standardized glucose infusion test (GIT). The insulin response to a GIT was analysed by parameter identification in a mathematical model that has been described in detail elsewhere [8]. The model assumes that glucose initiates insulin release by an immediate action (parameter KI). This parameter was previously used in designating subjects as HIR $(\mathrm{KI}>0.3)$ or LIR $(\mathrm{KI}<0.3)$. Criteria for HIR were arbitrarily set at KI $>0.6$ and for LIR at KI $<0.3$. The 
Table 1. Characteristics of subjects with high insulin response (HIR) and subjects with low insulin response (LIR)

\begin{tabular}{lllll}
\hline $\begin{array}{l}\text { Sub- } \\
\text { jects }\end{array}$ & $\begin{array}{l}\text { Age } \\
\text { (years) }\end{array}$ & $\begin{array}{l}\text { BMI } \\
\left(\mathrm{kg} / \mathrm{m}^{2}\right)\end{array}$ & $\begin{array}{l}\text { Mean insulin } \\
(\mu \mathrm{U} / \mathrm{ml}) \\
\text { during hyper- } \\
\text { glycaemic } \\
\text { clamp }\end{array}$ & $\begin{array}{l}\text { Blood glu- } \\
\text { cose }(\mathrm{mmol} / 1) \\
\text { during soma- } \\
\text { tostatin-insu- } \\
\text { lin-glucose- } \\
\text { infusion test }\end{array}$ \\
\hline HIR & $44.5 \pm 2.03$ & $23.3 \pm 0.85$ & $100.5 \pm 21.1$ & $6.22 \pm 0.93$ \\
LIR & $41.7 \pm 2.03$ & $23.4 \pm 0.91$ & $38.2 \pm 4.6$ & $5.57 \pm 0.83$ \\
\hline
\end{tabular}

${ }^{a}$ calculated as the mean of blood glucose determinations during 90-150 min of the test

hyperglycaemic clamps $(2 \mathrm{~h}$, glucose level $11 \mathrm{mmol} / \mathrm{l})$ which were then performed demonstrated 2.8-fold higher insulin levels in HIR than in LIR [4]. Insulin sensitivity between groups did not differ as assessed by $M / I$ ratios, i. e. amount of glucose infused divided by the mean insulin level during the clamp [4], or when assessed by a somatostatin-insulin-glucose infusion test [4, 9]. Six of eight HIR (all males) and seven of twelve LIR (six males, one female) from the latter study participated in the present one. Age and BMI did not differ between groups (Table 1). Similar to the original groups the insulin responses to hyperglycaemic clamps were 2.6 -fold higher in participating HIR than in LIR, $p<0.01$ for difference (Table 1 ), whereas the results of a somatostatin-insulin-glucose infusion test did not differ between groups (Table 1). Also M/I ratios betwen groups were similar (results not shown).

\section{Protocols}

All protocols used were approved by the Ethical Committee of the Karolinska Hospital. Subjects participated only after informed consent. All studies were performed after an overnight fast. Each subject was studied twice: in a control situation and during treatment with dexamethasone. Dexamethasone (Dexacortal, Organon Technica $\mathrm{AB}$, Boxtel, The Netherlands) was taken $3 \mathrm{mg}$ orally in the morning and at 22.00 hours for 2 days before the test and also on the morning of the test. At the latter time point, plasma levels of cortisol were depressed below $36 \mathrm{nmol} / \mathrm{in}$ all subjects.

One cannula (Venflon, Viggo, Helsingborg, Sweden) was inserted retrogradely into a dorsal vein for the sampling of blood. Another cannula was inserted into the antecubital vein in the contralateral arm and was used for administration of $\mathrm{L}$-arginine. A bolus injection $(150 \mathrm{mg} / \mathrm{kg}$ ) of $100 \mathrm{mg} / \mathrm{ml}$ of L-arginine hydrochloride was followed by infusion $\left(10 \mathrm{mg} \cdot \mathrm{kg}^{-1} \cdot \mathrm{min}^{-1}\right)$ of the amino acid.

\section{Assays}

Blood glucose was determined with a glucose oxidase method using a glucose analyser (Yellow Springs Instruments, Yellow Springs, Ohio, USA). Immunoreactive insulin (subsequently referred to as insulin) was measured by RIA using antibodies raised in our laboratory and charcoal addition [10] to separate bound and free insulin. Interassay coefficient of variation (CV) was $9.7 \%$ and intraassay $\mathrm{CV}, 5.0 \%$. Cross-reactivity with proinsulin was approximately $100 \%$. C-peptide was also determined by RIA with a commercially available kit (RIA-gnost, Behringwerke AG, Frankfurt, FRG). The intraassay $C V$ was $7 \%$ and the interassay variation was $6 \%$.

\section{Statistical analysis}

All values are given as mean $\pm S E M$. Secretion of insulin was calculated for periods of stimulation using the trapezoidal rule. Statistical analysis included two-tailed Student's $t$-test, for paired or unpaired differences as evident from the text.

\section{Results}

\section{Blood glucose}

Levels of blood glucose in the fasting state were $4.43 \pm 0.17 \mathrm{mmol} / 1$ in HIR and $4.62 \pm 0.11 \mathrm{mmol} / 1$ in LIR. The difference was not significant. During $30 \mathrm{~min}$ of arginine stimulation, levels were slightly but significantly increased in HIR $(p<0.001)$ and in LIR $(p<0.005)$. The mean level of blood glucose during arginine stimulation was $5.02 \pm 0.16 \mathrm{mmol} / \mathrm{l}$ in HIR and $5.46 \pm 0.14 \mathrm{mmol} / \mathrm{l}$ in LIR; the difference was not significant $(p<0.1)$.

Dexamethasone treatment significantly increased fasting blood glucose in HIR to $5.28 \pm 0.30 \mathrm{mmol} / \mathrm{l}, p<0.02$ and in LIR to $5.75 \pm 0.17 \mathrm{mmol} / 1, p<0.005$. During arginine stimulation and dexamethasone treatment glucose levels were increased in both groups but less in HIR than in LIR (6.15 \pm 0.24 vs $6.69 \pm 0.10 \mathrm{mmol} / \mathrm{l}, p<0.05)$.

\section{Insulin and C-peptide}

Fasting levels of insulin did not differ between HIR and LIR (Table 2). Administration of arginine induced a diphasic increase in insulin levels in both HIR and LIR (Fig. 1). The 0-10 $\mathrm{min}$ response was 2.5 -fold greater in HIR than in LIR, $p<0.01$ (Table 2). The total response (0-30 $\mathrm{min}$ ) was 1.7-fold greater in HIR than in LIR but the difference was not significant $(p<0.1)$.

Dexamethasone treatment increased fasting levels of immunoreactive insulin 1.9-fold in HIR and 1.6-fold in LIR (Table 2). During dexamethasone treatment the early $(0-10 \mathrm{~min})$ response to arginine was increased 1.4-fold and the total response 2.0-fold in HIR (Fig. 1, Table 2). By contrast, the response to arginine was unaffected in LIR: the early response during dexamethasone treatment was 1.1-fold and the total response 1.0-fold of that observed during control conditions. Accordingly, during dexamethasone treatment the early response to arginine was only $32 \%$ and the total response only $31 \%$ of that seen in HIR.

Results on C-peptide paralleled those on insulin, albeit with lesser significant differences between HIR and LIR. Fasting levels of C-peptide were similar in HIR and LIR (Table 3). Arginine caused a mean 2.6-fold increase in HIR and a 2 -fold increase in LIR (Fig. 1, Table 3). During

Table 2. Effects of L-arginine on serum levels of immunoreactive insulin

\begin{tabular}{lllll}
\hline $\begin{array}{l}\text { Sub- } \\
\text { jects }\end{array}$ & Treatment & $\begin{array}{l}\text { Before } \\
\text { arginine } \\
(\mu \mathrm{U} / \mathrm{ml})\end{array}$ & $\begin{array}{l}\text { Increment during arginine } \\
(\mu \mathrm{U} / \mathrm{ml})^{\mathrm{a}}\end{array}$ \\
\cline { 4 - 5 } & $0-10 \mathrm{~min}$ & $0-30 \mathrm{~min}$ \\
\hline $\mathrm{HIR}^{\mathrm{b}}$ & - & $12.8 \pm 1.3$ & $36.5 \pm 6.8$ & $33.7 \pm 5.9$ \\
LIR $^{\mathrm{b}}$ & - & $12.6 \pm 1.2$ & $14.5 \pm 2.3^{\mathrm{c}}$ & $19.9 \pm 4.2$ \\
HIR & Dexamethasone & $24.8 \pm 3.5$ & $51.2 \pm 8.5$ & $67.1 \pm 10.2$ \\
LIR & Dexamethasone & $19.9 \pm 2.1$ & $16.3 \pm 2.7^{\mathrm{c}}$ & $20.7 \pm 3.0^{\mathrm{c}}$ \\
\hline
\end{tabular}

${ }^{a}$ mean \pm SEM;

${ }^{\mathrm{b}} \mathrm{HIR}$, subjects with high insulin response, LIR, subjects with low insulin response;

${ }^{c} p<0.01$ or less, significance of difference LIR vs HIR 

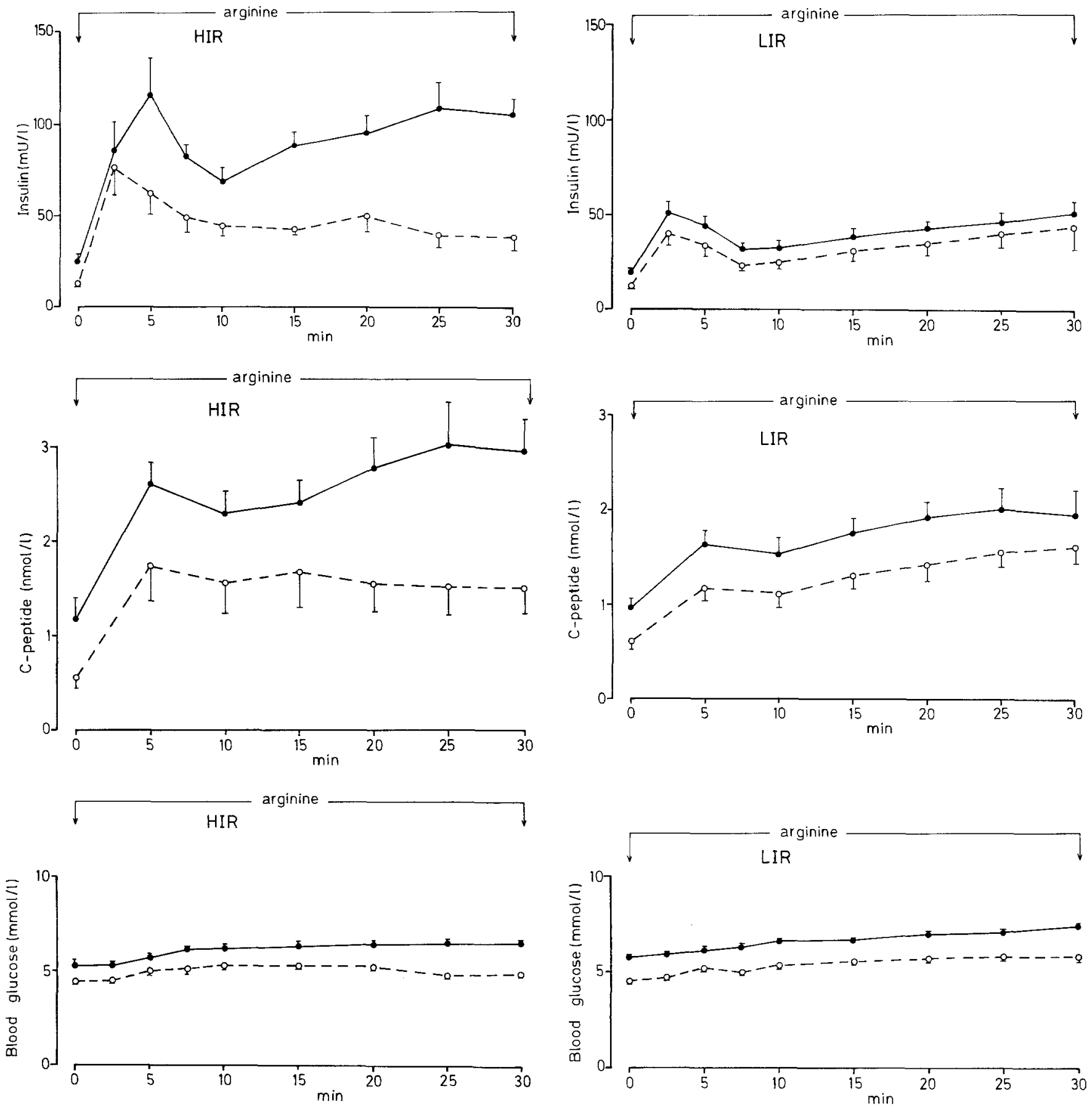

Fig. 1. Effects of L-arginine on levels of glucose, insulin and C-peptide, $-\mathrm{O}-=$ control, $-\mathbf{-}-$ during dexamethasone. HIR, subjects with high insulin response; $L I R$, subjects with low insulin response

dexamethasone treatment the C-peptide response to arginine was increased 1.4-fold in HIR and 1.1-fold in LIR. This difference in arginine-induced response during dexamethasone treatment between groups was significant $(p<0.05)$.

\section{Discussion}

Our results confirm and extend previous data [5] on arginine-induced insulin secretion in LIR, showing a lesser response in LIR than in HIR to the amino acid during fast- ing baseline conditions. The present study unequivocally demonstrates that the difference between groups cannot be explained by lower levels of glycaemia in LIR leading to less potentiation by glucose of the arginine response. Hence the levels of blood glucose during arginine stimulation were similar or, if anything, slightly higher in LIR than in HIR.

We furthermore demonstrate for the first time failure of dexamethasone treatment to augment arginine-induced insulin secretion in LIR. We have previously shown [4] that enhancement during dexamethasone treatment of 
Table 3. Effects of L-arginine on serum levels of immunoreactive C-peptide (nmol/l)

\begin{tabular}{lllll}
\hline $\begin{array}{l}\text { Sub- } \\
\text { jects }\end{array}$ & Treatment & $\begin{array}{l}\text { Before } \\
\text { arginine }\end{array}$ & $\begin{array}{l}\text { During arginine } \\
(0-30 \mathrm{~min})\end{array}$ \\
\cline { 3 - 5 } & & & Absolute & Increment \\
\hline HIR $^{\mathrm{a}}$ & - & $0.55 \pm 0.10$ & $1.46 \pm 0.27$ & $0.91 \pm 0.18$ \\
LIR $^{\mathrm{a}}$ & - & $0.59 \pm 0.07$ & $1.26 \pm 0.13$ & $0.66 \pm 0.08$ \\
HIR & Dexamethasone & $1.18 \pm 0.22$ & $2.48 \pm 0.28$ & $1.30 \pm 0.11$ \\
LIR & Dexamethasone & $0.97 \pm 0.10$ & $1.69 \pm 0.15^{\mathrm{b}}$ & $0.73 \pm 0.11^{\mathrm{b}}$ \\
\hline
\end{tabular}

${ }^{a}$ HIR, subjects with high insulin response, LIR, subjects with low insulin response

${ }^{\mathrm{b}} p<0.05$ or less, significance of difference LIR vs HIR

glucose-induced insulin secretion is less in LIR than in HIR, although intra-group variation is considerable. The present results with arginine-induced insulin secretion show a possibly greater difference in responsiveness between LIR and HIR than with glucose. Furthermore, our results with $\mathrm{C}$-peptide indicate that the differences in response to arginine between groups are not due to differences in insulin removal. C-peptide which co-secretes with insulin is not, as insulin, to a major extent extracted by the liver [11]. Hence the findings that arginine-induced stimulation of C-peptide showed differences between LIR and HIR that were similar to those found for insulin indicate that the insulin responses measured reflect true secretion rates.

What do the findings with dexamethasone signify in terms of physiology or pathophysiology? In non-diabetic rats [12] as well as in man [13], dexamethasone treatment for 2-4 days moderately increases Beta-cell secretory responsiveness. This enhancement can be viewed as an appropriate response of the Beta-cell brought about by the increased demands from the steroid-induced insulin resistance acting, probably, through minimal increases in blood glucose. The clamp studies performed indicated that dexamethasone markedly reduced (by about $50 \%$ ) insulin sensitivity in both groups. Hence dexamethasoneinduced insulin resistance should have provided as much impetus for augmenting insulin secretion in LIR as in HIR.

Failure of dexamethasone to enhance arginine-induced insulin secretion in LIR could be due to a decreased potentiating-sensing effect of glucose on arginine-induced insulin release and/or to a generalized defect in the releasing capacity of all secretagogues. These alternatives cannot be completely evaluated from in vivo studies in man. Several observations in animals with decreased Beta-cell capacity are however relevant to such evaluation. In dogs which have been partially pancreatectomized but retain normoglycaemia, decreased responses to arginine at normoglycaemia as well as decreased potentiating effect of rising concentrations of glucose are observed [14]. Of particular relevance to the present results during dexamethasone treatment are recent observations in $50 \%$ pancreatectomized normoglycaemic rats [12], which were treated with glucocorticoids for 4 days. While control rats showed markedly increased insulin responses to arginine during dexamethasone treatment the partly pancreatectomized rats did not. The evidence from ani- mal experiments makes our results compatible with a moderately reduced Beta-cell capacity in LIR. However evidence at hand cannot exclude the possibility of a sensing defect being alternatively or additionally present.

The failure of LIR to increase insulin responses during insulin resistance is compatible with increased susceptibility to development of Type 2 diabetes. Such a notion has also previously been proposed, i. e. subjects with decreased oral glucose tolerance after acute administration of cortisone have been proposed to run an increased risk of developing the disease [15]. This notion is also supported by our own findings showing that glucose tolerance decreases more during dexamethasone treatment in LIR than in HIR [16]. Whether our results are representative of a majority rather than a subgroup of the LIR population has however not been established. It remains also to be tested whether LIR could increase Beta-cell responsiveness following insulin resistance induced by means other than dexamethasone treatment (to exclude the possible influence of direct effecs of glucocorticoids) or following a longer period of resistance than the present one.

Acknowledgements. This study was supported by the Swedish Medical Research Council (grants no 04540 and 0034), The Swedish Diabetes Association and the Nordic Insulin Foundation. The dedicated nursing assistance of Ms. K. Waldelöf is gratefully acknowledged.

\section{References}

1. Cerasi E, Luft R (1967) The plasma insulin response to glucose infusion in healthy subjects and in diabetes mellitus. Acta Endocrinol 55: 278-304

2. EfendicS, Luft R, Wajngot A (1984) Aspects of the pathogenesis of type 2 diabetes. Endocrine Rev 5: 395-408

3. Kosaka K, Hagura R, Kuzuya T (1977) Insulin responses in equivocal and definite diabetes, with special reference to subjects who had mild glucose intolerance but later developed definite diabetes. Diabetes 26: 944-952

4. Grill V, Pigon J, Hartling SC, Binder C, Efendic S (1990) Effects of dexamethasone on glucose-induced insulin and pro-insulin release in low and high insulin responders. Metabolism 39:251-258

5. Assan R, Efendic S, Luft R, Cerasi E (1981) Dose-kinetics of pancreatic glucagon responses to arginine and glucose in subjects with normal and impaired pancreatic B cell function. Diabetologia 21: $452-459$

6. Johnston C, Raghu P, McCulloch DK et al. (1987) $\beta$-cell function and insulin sensitivity in non-diabetic HLA-identical siblings of insulin-dependent diabetics. Diabetes 36: 829-837

7. World Health Organization Expert Committee on Diabetes Mellitus (1985) Technical report series 727. Geneva

8. Cerasi E, Fick G, Rudemo M (1974) A mathematical model for the glucose-induced insulin release in man. Eur J Clin Invest 4: 267-278

9. Bergman RN, Finegood DT, Ader M (1985) Assessment of insulin sensitivity in vivo. Endocrine Rev 6: $52-58$

10. Herbert V, Lau KS, Gottlieb CW, Bleicher SJ (1965) Coated charcoal immunoassay of insulin. J Clin Endocrinol Metab 25: $1375-1384$

11. Polonsky J, Jaspan J, Pugh W et al. (1983) Metabolism of C-peptide in the dog. J Clin Invest 72: 1114-1123

12. Orland MJ, Permutt MA (1991) Comparative modulations of insulin secretion, pancreatic insulin content and proinsulin mRNA 
in rats. Effects of $50 \%$ pancreatectomy and dexamethasone administration. Diabetes 40: 181-189

13. Beard JC, Halter JB, Best JD, Pfeifer MA, Porte D (1984) Dexamethasone-induced insulin resistance enhances $B$ cell responsiveness to glucose levels in normal men. Am J Physiol 247: E592-E596

14. Ward WK, Wallum BJ, Beard JC, Taborsky GJ, Porte D (1988) Reduction of glycemic potentiation. Sensitive indicator of $\beta$-cell loss in partially pancreatectomized dogs. Diabetes 37: 723-729

15. Rull JA, Conn JW, Floyd JC et al. (1970) Levels of plasma insulin during cortisone glucose tolerance tests in "nondiabetic" relatives of diabetic patients. Implications of diminished insulin secretory reserve in subclinical diabetes. Diabetes 19: 1-10
16. Wajngot A, Grill V, Vranic M, EfendicS (1990) The diabetogenic effects of glucocorticoids are more pronounced in low than in high insulin responders. Diabetologia 33: A59 (Abstract)

Received: 23 August 1991

and in revised form: 2 December 1991

Dr. V.Grill

Department of Endocrinology

Karolinska Hospital

S-104 01 Stockholm

Sweden 